\title{
NARRATIVAS DE IMIGRANTES DO PASSADO E DO PRESENTE: QUESTÕES PARA PESQUISA
}

\section{ZEILA DE BRITO FABRI DEMARTINI}

Centro de Estudos Rurais e Urbanos, Universidade de São Paulo

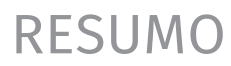

Tratar de processos imigratórios no Brasil significa compreender um período histórico bem alargado. Considera-se que a abordagem biográfica, em suas diferentes vertentes, muito tem contribuído para a ampliação dos conhecimentos sobre os "outros" que foram chegando em território brasileiro. As narrativas dos sujeitos imigrantes são objeto de pesquisas, recorrendo às diferentes formas sob as quais podem ser obtidas e que os colocam como participantes na produção de conhecimento. Este texto traz à tona possibilidades da pesquisa biográfica, procurando salientar sua importância para a compreensão dos contextos migratórios, dos dilemas enfrentados pelos imigrantes e de suas vivências. Aborda, inicialmente, as possibilidades colocadas para períodos mais remotos, nos quais foram estudados relatos autobiográficos e cartas. Depois, trata de pesquisas mais recentes, em que o acesso aos próprios imigrantes foi possivel, recorrendo-se a histórias de vida e a depoimentos, por meio de narrativas orais. Trata-se, assim, de estudos de natureza diferente: o primeiro caso é sobre os imigrantes; o segundo os incorpora e com eles dialoga. A pesquisa de abordagem biográfica tornou-se fundamental para a discussão das questões envolvendo os imigrantes, principalmente pelo fato de considerá-los como "sujeitos", mesmo quando são considerados como "outros", pela sociedade, e como ameaças, pelo Estado brasileiro.

Palavras-chave: Imigrantes. Pesquisa biográfica. Autobiografias, cartas e narrativas orais.

\section{ABSTRACT NARRATIVES OF IMMIGRANTS FROM THE PAST AND THE PRESENT: RESEARCH QUESTIONS}

The study of immigration processes in Brazil covers a lengthy historic period and the biographical approach in its different aspects has contributed significantly to the expansion of knowledge about these "others" in Brazilian territory. Migrant narratives are object of many different attentions but by being obtained in a research process they pose migrants as participants in the production of fundamental knowledge. This text brings up the possibilities of biograph- 
ical research stressing its importance for the realistic understanding of migratory contexts, of the dilemmas faced by immigrants and concrete experiences. It discusses the possibilities initially placed for more remote periods, which have been studied on the basis of autobiographical accounts and letters. After this, it deals with more recent research in which access to the very immigrants was possible, using life stories and testimonials by means of oral narratives. The first case is about immigrants; the second incorporates them and dialogues with them along the research process. The centrality of this approach relies on the fact that it considers migrants as "subjects", even when they are considered as the threatening "other" by society or by the State.

Keywords: Immigrants. Biographical research. Autobiography, letters and oral narratives.

\section{NARRATIVAS DE INMIGRANTES DEL PASADO Y DEL PRESENTE: CUESTIONES PARA LA INVESTIGACIÓN}

Tratar de procesos inmigratorios en Brasil significa comprender un período histórico bien ampliado. Se considera que el abordaje biográfico, en sus diferentes vertientes, ha contribuido mucho a la ampliación de los conocimientos sobre los "otros" que se llegaron en territorio brasileño. Las narrativas de los sujetos inmigrantes son objeto de investigaciones, recurriendo a las diferentes formas bajo las cuales pueden ser obtenidas y que los colocan como participantes en la producción de conocimiento. Este texto trae a la superficie posibilidades de la investigación biográfica, buscando resaltar su importancia para la comprensión de los contextos migratorios, de los dilemas enfrentados por los inmigrantes y sus vivencias. Aborda, inicialmente, las posibilidades colocadas para períodos más remotos, en los que se estudiaron relatos autobiográficos y cartas. Después, trata de investigaciones más recientes, en que el acceso a los propios inmigrantes fue posible, recurriendo a historias de vida ya testimonios, por medio de narrativas orales. Se trata, pues, de estudios de naturaleza diferente: el primer caso es sobre los inmigrantes; el segundo los incorpora y con ellos dialoga. La investigación de abordaje biográfico se ha vuelto fundamental para la discusión de las cuestiones involucrando a los inmigrantes, principalmente por el hecho de considerarlos como "sujetos", aun cuando son considerados como "otros", por la sociedad, y como amenazas, por el Estado brasileño.

Palabras clave: Los inmigrantes. Búsqueda biográfica. Autobiografías, cartas y narraciones orales. 


\section{Introdução}

Deslocamentos marcam as experiências e as memórias de grande parte da população, atualmente, e desde tempos muito remotos. Forçados, ou por contingências de ordem variada, grupos e sujeitos movimentaram-se de um contexto para outro, seja fugindo do seu local de origem, seja invadindo territórios de outros. De uma forma ou de outra, as marcas dos que chegam e dos que saem permeiam a história da humanidade e dos territórios ocupados pelo homem, demandando estudos sobre os deslocamentos, em eras pretéritas, sobre os quais restaram apenas vestígios arqueológicos. As denominações para tais deslocamentos variam, principalmente, a partir da perspectiva dos sujeitos envolvidos: invasores, conquistadores, colonizadores, emigrantes, imigrantes, migrantes, refugiados, clandestinos, nômades?

Da mesma forma, para os pesquisadores, tais perspectivas, mesmo que inconscientemente, permeiam a escolha de seus problemas de investigação e seus projetos, envolvendo diferentes abordagens teórico-metodológicas e técnicas de investigação. Para períodos mais recentes, ampliam-se as possibilidades de acesso a fontes. Focalizando os chamados migrantes, emigrantes e imigrantes, também se torna mais próximo o acesso aos sujeitos "deslocantes". Nesse caso, a pesquisa, recorrendo à abordagem biográfica, em suas várias modalidades, tem contribuído com estudos importantes sobre os processos migratórios. Trataremos a seguir de alguns aspectos dessa temática.

\section{Imigração e abordagem biográfica}

$\mathrm{Na}$ atualidade, o tema da imigração tem ocupado os espaços da mídia e da produção acadêmica, principalmente em virtude dos grandes deslocamentos de populações, que fogem de situações de guerra e de extrema pobreza, de países do Oriente Médio e do continente africano, em direção à Europa, demandando providências dos Estados nacionais, em seu atendimento. As tensões se avolumaram, levando a intensificar ou iniciar estudos sobre os deslocados e sobre os territórios de onde saíram, que de certo modo não estavam sendo objeto de reflexão, desde os processos de independência dos países que foram colonizados até a segunda metade do século XX. A produção europeia geralmente voltava-se para as levas de imigrantes refugiados que saíam da Europa, fugindo das situações precárias, das guerras mundiais e dos regimes totalitários e suas perseguições a determinados grupos. A preocupação com o "outro" que chega é assim mais recente nos estudos europeus. Segundo Enrique Santamaría, embora a subida de migrantes procedentes dos países denominados do Terceiro Mundo tenha acontecido desde o final dos anos sessenta, é somente na metade dos anos oitenta que o imigrante começa a ser visível socialmente (SANTAMARÍA, 1998)

No Brasil, entretanto, a chegada de novos sujeitos sempre superou a saída da população do país. 0 estudo dos que chegavam ao território brasileiro acompanhou primeiramente os sujeitos que vieram como escravos da África e, a partir da segunda metade do século XIX, os milhares de imigrantes europeus e depois asiáticos e latino-americanos. A produção de fontes sobre deslocamentos de populações foi assim sendo objeto de estudos, em vários campos disciplinares (embora a Universidade aqui só tenha sido implantada recentemente). Não são, entretanto, considerados como imigrantes, nos estudos, os que vieram da África como escravos, embora algumas vertentes históricas tentem incorporá-los a essa categoria, como parte da diáspora africana: mas não vieram como trabalhadores livres e, sim, aprisio- 
nados, vendidos e tratados como mercadoria. são sobre imigração, pelo menos até o término Não podemos assim incorporá-los na discus- do regime escravocrata.

Quadro 1 - População Estrangeira nas Províncias e Estados Brasileiros. Censos de 1872 a 1980.

\begin{tabular}{|c|c|c|c|c|c|c|c|c|}
\hline Estados & 1872 & 1890 & 1900 & 1920 & 1940 & 1950 & 1970 & 1980 \\
\hline Alagoas & 3.718 & 536 & 838 & 693 & 511 & 421 & 524 & 606 \\
\hline Amazonas & 2.199 & 3.277 & 1.882 & 16.936 & 7.441 & 5.192 & 3.701 & 3.767 \\
\hline Bahia & 22.397 & 26.776 & 9.071 & 16.699 & 8.007 & 8.224 & 9.685 & 9.875 \\
\hline Ceará & 1.592 & 534 & 859 & 901 & 1.372 & 1.206 & 1.429 & 1.838 \\
\hline Distrito Federal & - & - & - & - & - & - & 4.584 & 7.920 \\
\hline Espírito Santo & 4.191 & 3.074 & 21.420 & 18.754 & 10.043 & 5.507 & 3.204 & 2.698 \\
\hline Goiás & 367 & 62 & 86 & 1.694 & 2.507 & 3.667 & 5.653 & 4.607 \\
\hline Maranhão & 5.247 & 606 & 939 & 1.586 & 1.288 & 1.008 & 1.070 & 1.135 \\
\hline Mato Grosso & 1.669 & 958 & 11.167 & 25.321 & 23.207 & 19.753 & 24.937 & - \\
\hline M. Grosso Norte & - & - & - & - & - & - & - & 3.033 \\
\hline Mato Grosso Sul & - & - & - & - & - & - & - & 11.379 \\
\hline Minas Gerais & 46.900 & 46.787 & 91.593 & 85.705 & 45.546 & 32.896 & 25.321 & 19.937 \\
\hline Pará & 6.529 & 4.039 & 2.201 & 22.083 & 11.074 & 8.215 & 8.866 & 7.294 \\
\hline Paraíba & 843 & 180 & 345 & 602 & 671 & 516 & 592 & 1.066 \\
\hline Paraná & 3.627 & 5.153 & 39.786 & 62.753 & 66.653 & 76.592 & 80.497 & 42.811 \\
\hline Pernambuco & 13.444 & 2.690 & 4.240 & 11.698 & 6.720 & 5.551 & 6.386 & 5.701 \\
\hline Piauí & 653 & 19 & 97 & 326 & 285 & 258 & 270 & 310 \\
\hline RJ - Guanab. & 184.182 & 140.492 & 246.272 & 289.960 & 267.367 & 248.849 & 283.742 & 216.266 \\
\hline R. G. Norte & 997 & 152 & 179 & 327 & 451 & 453 & 389 & 801 \\
\hline R. G. Sul & 41.725 & 34.765 & 135.099 & 151.025 & 109.470 & 78.138 & 51.079 & 36.813 \\
\hline Santa Catarina & 16.974 & 6.198 & 29.550 & 31.243 & 27.201 & 19.067 & 10.188 & 7.496 \\
\hline São Paulo & 29.622 & 75.030 & 478417 & 829.851 & 814.102 & 693.321 & 703.526 & 523.444 \\
\hline Sergipe & 2.583 & 270 & 270 & 397 & 290 & 184 & 250 & 555 \\
\hline Acre & - & - & - & 3.506 & 1.236 & 1.144 & 704 & 551 \\
\hline Fer. N./Ap & - & - & - & - & 000 & $2 / 504$ & $6 / 395$ & $-/ 339$ \\
\hline Roraima & - & - & - & - & 000 & 2.094 & 1.837 & 663 \\
\hline Rondônia & - & - & - & - & 000 & 420 & 299 & 1.943 \\
\hline Brasil & 389.459 & 351.545 & 1.074 .671 & 1.565 .961 & 1.405 .442 & 1.213.182 & 1.229.134 & 912.848 \\
\hline
\end{tabular}

Fonte: Levy (1974, p. 13). In BASSANEZI (1996, p.13).

Tratar, assim, de processos imigratórios no Brasil significa compreender um período histórico bem alargado, ao menos desde meado do século XIX (DEMARTINI, 2010). E consideramos que a abordagem biográfica, em suas diferentes vertentes, muito tem contribuído para a ampliação dos conhecimentos sobre esses "outros" que foram chegando ao território brasileiro. No Brasil, os "outros" foram muitos, se considerarmos o período que se estende desde a chegada dos primeiros imigrantes, para substituir a mão de obra escrava, até o 
início do século XXI; constata-se que a diversidade sempre foi muito grande, e que várias regiões do país passaram a incorporá-los. É importante olhar para os dados que indicam essa presença, para melhor compreendermos a importância da pesquisa sobre os diferentes grupos que passaram a compor a população brasileira, e que continuam chegando, vindo de diferentes partes do mundo.

O Estado de São Paulo, lócus de estudo sobre a imigração, constituiu-se historicamente como um território de sujeitos de várias origens, cores e credos.

Desde meados do século XIX, começaram a entrar nesse estado grandes levas de imigrantes vindos de diferentes regiões do mundo (IANNI, 1967). No século XIX, chegaram inicialmente muitos alemães, italianos e portugueses, ao lado de povos de outras origens. No século XX, continuaram entrando imigrantes dessas origens, mas também se iniciou a imigração oriental, com a grande entrada de japoneses a partir de 1908 (BASSANEZI, 1996). Segundo dados de 1980, os estrangeiros no Estado de São Paulo eram originários de diferentes regiões: havia 174.089 portugueses, 89.361 japoneses, 60.280 italianos, 57.369 espanhóis, 15.474 alemães e 126.871 outros. Em tais dados não estão incorporados os descendentes, que acrescentariam um número muito maior de sujeitos ligados aos grupos (ATLAS da População do Estado de São Paulo, 1991).

De modo geral, os imigrantes vieram tentando superar dificuldades em seus contextos de origem, com aspiração de ascensão econômica e, para muitos, com visualização de retorno às regiões de origem. Cada leva de imigrantes apresentou características próprias, tendo estabelecido relações diferenciadas com 0 contexto paulista.

Essa complexidade é que instiga pesquisadores de várias formações disciplinares a tentar compreender porque e como vieram, que vivências passaram a ter no novo contexto, como foram construindo sua nova história, as marcas que foram deixando nos vários campos de suas experiências de vida (na economia, na educação, na cultura, na política etc.); desvendar legados que, aos poucos, cada um imprimiu na paisagem, na composição da população, na alimentação, no modos de ver e sentir a vida, nos projetos desenvolvidos, no imaginário e na memória sobre o contexto vivido são desafios para os que trabalham com a temática migratória. Ressaltamos o que Sayad (2000) tão bem observou: os imigrantes carregam as marcas de seu contexto de origem, e, ao mesmo tempo, sofrem as do contexto de adoção.

Por tais razões, é possivel afirmar que os contextos que recebem muitos imigrantes são marcados por experiências múltiplas que se cruzam, sobre os quais constroem-se identidades e memórias também múltiplas. Pollack (1992), ao refletir sobre a questão, chama a atenção para o fato de que a memória é um fenômeno construído social e individualmente, daí sua ligação com o sentimento de identidade. Destaca, como elementos constitutivos da memória: os acontecimentos vividos pessoalmente ou de forma indireta, muitas vezes pela família; as pessoas e personagens envolvidas e os chamados lugares da memória, ligados às vivências do sujeito.

Como apreender as várias experiências e as várias memórias dos inúmeros imigrantes, em diferentes épocas?

A procura por fontes que permitam esclarecer as experiências dos sujeitos envolvidos em processos migratórios tem permitido que os imigrantes deixem de ser apenas números quantificados a partir de documentos de embarque, de listas de navios, de relatórios de chegada, de censos demográficos, e passem a ser compreendidos por meio de fontes biográficas que os colocam como protagonistas 
da história, com seus projetos, opções, problemas, desilusões, novos sonhos, superações, enfim, como sujeitos que, por motivos variados, se deslocam (ou vagueiam nos dias atuais), em busca de melhores condições de trabalho e de vida.

A abordagem biográfica tem permitido que o conhecimento seja produzido nessa direção. As narrativas dos sujeitos migrantes são objeto de pesquisas, recorrendo às diferentes formas sob as quais podem ser obtidas e que colocam os imigrantes como participantes da produção de conhecimento, na medida em que são eles que produzem as narrativas a serem analisadas, sobre eles próprios.

Dada a longa duração dos processos de chegada de imigrantes no Brasil e sua diferenciação, muitas possibilidades (mas também dificuldades) apresentam-se aos pesquisadores. De algum modo, o acesso às fontes de pesquisa depende das características dos imigrantes em seus contextos de origem e as relações que eles mantêm: os registros materiais de sua cultura, os processos de escrita ou sua ausência, os contatos estabelecidos entre os que ficaram, entre outras. Depende, ainda, do período em que chegaram, pois variaram os meios de transporte e a documentação exigida pelo Estado brasileiro, para a entrada no território, assim como a legislação de controle da imigração. Em solo brasileiro, outros fatores também podiam influenciar, em épocas passadas, na maior ou menor existência de fontes disponibilizadas para a pesquisa: a existência de instituições de apoio aos imigrantes, estatais ou particulares, como igrejas, escolas, associações; as possibilidades de estabelecer contato (por cartas) com outros imigrantes do mesmo grupo, no Brasil ou no país de origem; a participação em eventos e associações, os hábitos de escrita sobre as experiências vivenciadas, individualmente ou pelo grupo, e até sua participação em processos na justiça (MONSMA, 2005). Em épocas mais próximas, além dessas possibilidades, outras se colocam como as que são cada vez mais utilizadas: tecnologias digitais, gravações em áudio e vídeo, que permitem o contato direto com o sujeito. São importantes também os locais pelos quais passavam os imigrantes (e migrantes), em sua chegada; em São Paulo, a Hospedaria dos Imigrantes, por onde passaram centenas de milhares vindos de várias partes do mundo, registrou as marcas dessas passagens desde 1889, e continua acolhendo os novos imigrantes. No Rio de Janeiro, a Ilha das Flores também acolheu os imigrantes. Atualmente, são importantes centros de consulta para pesquisadores da temática de imigração.

Embora diversificadas, o acesso às fontes e aos sujeitos nem sempre é possível aos pesquisadores. Para épocas mais remotas, tem-se que contar com o fato de que muitos documentos se deterioraram-se com o tempo, foram jogados fora ou foram perdidos pelos descendentes dos que vieram e, ainda, queimados ou enterrados nos períodos de perseguição, por parte do Estado Brasileiro, nas décadas de 1930 e 1940.

Ao mesmo tempo, também os próprios imigrantes, seus descendentes e pesquisadores começaram a intensificar a busca de suas "raízes", surgindo inúmeros levantamentos ligados a associações de grupos e a famílias. Esta procura foi, em parte, associada ao fato de que muitos brasileiros, a partir da década de 1980, se voltaram para o caminho inverso, isto é, procuraram fazer a vida em outros países. Para muitos, ser descendentes de imigrantes podia facilitar o processo de entrada em outros países, como foi o caso de centenas de milhares de decasséguis, de italianos, de alemães, espanhóis. Surgiram, nas últimas décadas, novas reflexões sobre as trajetórias empreendidas pelos imigrantes, muitos estudos biográficos 
e até o interesse em colocar suas documentações em centros de memória.

Nas últimas décadas, também se intensificaram as entradas de imigrantes que vieram para o Brasil procurando inserir-se na universidade, apresentando em perfil diferenciado dos que vinham para trabalhar, o que de certa forma facilitou o acesso a grupos que entraram mais recentemente, dado seu conhecimento e identificação com muitos deles.

\section{As narrativas de imigrantes na pesquisa biográfica}

Nossa opção nesse texto foi trazer à tona possibilidades da pesquisa biográfica, com base em algumas das fontes mencionadas acima, procurando salientar sua importância para essa discussão, para a compreensão dos contextos migratórios e dos dilemas vivenciados pelos imigrantes.

Abordamos, inicialmente, as possibilidades colocadas para períodos mais remotos, sobre as quais foram estudados relatos autobiográficos e cartas. Depois tratamos de pesquisas mais recentes, em que o acesso aos próprios imigrantes foi possivel, recorrendo-se às suas histórias de vida e depoimentos por meio de narrativas orais.

Trata-se, assim, de estudos de natureza diferente: o primeiro caso é sobre os imigrantes; o segundo os incorpora e com eles dialoga.

\section{Autobiografias e Cartas de Imigrantes: memórias dos ausentes}

A pesquisa que focaliza períodos mais remotos tem procurado levantar documentos escritos pelos imigrantes, relatos autobiográficos, cartas, incorporando tais narrativas ao estudo da imigração. Thomas e Znaniecki, em seu clássico estudo The Polish Peasant in Europe and
America. A Classic Work in Immigration History (1958), recorreram a correspondências e ao depoimento escrito do imigrante polonês Wladeck Wiszniewski, para uma análise das transformações dos comportamentos dos camponeses poloneses, após seu contato com o mundo urbano moderno, e sua migração para os Estados Unidos. Obra escrita entre 1918 e 1920, tornou-se referência, nos estudos sobre migração, principalmente pelo ineditismo no uso de documentos pessoais. (EUFRÁSIO, 2006; OLIVEIRA, 2014).

Esse trabalho transformou-se em referência para os pesquisadores que estudam a temática da imigração, estimulando-os a buscarem fontes documentais ainda pouco exploradas para a apreensão de diferentes dimensões do processo migratório e das especificidades de cada grupo imigrante, em diferentes contextos e períodos históricos.

No Brasil, tais fontes foram ainda produzidas por imigrantes, também poloneses, e analisadas por Seyferth (2005). A antropóloga recorreu a cartas e narrativas de trajetórias individuais sobre o processo imigratório de poloneses ocorrido no Sul do Brasil no século XIX. Em seu estudo, fez comparações com o trabaIho de Thomas e Zaniecki:

Aquele trabalho propõe a compreensão de problemas sociais por meio das histórias pessoais, resultando em uma perspectiva interdisciplinar que privilegiou os princípios teóricos e as técnicas da Psicologia Social. Seu objetivo não era, propriamente, a história de um processo migratório; tratava-se de compreender a dinâmica da mudança social envolvendo a transferência de população de uma sociedade rural para uma sociedade urbana em um contexto imigratório. Portanto, o objeto era sociológico, e não histórico. É nesse sentido que o registro (life record) e as cartas são utilizados como fontes, no caso, escritas. (SEYFERTH, 2005, p. 41)

A pesquisa realizada pôs em evidência certos aspectos da imigração e da ocupação ter- 
ritorial nem sempre disponiveis na documentação e na historiografia da colonização, no sul do Brasil, e observa que:

Como indicadores de trajetórias pessoais, as autobiografias escritas espontaneamente, em um dado momento da vida de um indivíduo que quis registrar sua experiência imigratória, são igualmente importantes no contexto da imigração no Sul do Brasil. Conforme assinalou Sayad (1998), emigração e imigração tem dupla dimensão: de fato coletivo e itinerário individual, daí a importância das trajetórias, experiências singulares por meio do movimento do emigrante a se tornar imigrante. Em vario de seus escritos, Sayad utiliza discursos de informantes cujo conteúdo remete a uma teoria da emigração/ imigração, dando conta de diferentes aspectos da vida dos argelinos emigrados para a França. Entretanto, faz questão de lembrar uma 'banalidade' um tanto óbvia, mas nem sempre considerada: a imigração é um fato social total, portanto referida à sociedade como um todo, em uma perspectiva diacrônica e sincrônica (Sayad, 1998, p. 16). (SEYFERTH, 2005, p 46)

A autora destaca a importância das narrativas para a compreensão do processo imigratório de poloneses, no Sul do Brasil, ainda no século XIX:

As narrativas contêm elementos elucidativos da emigração e chamam a atenção para a manutenção dos laços familiares com os que ficaram na sociedade de origem e o empenho em trazer os parentes mais próximos para o brasil, apesar das dificuldades da travessia (incluindo, no caso dos poloneses, os entraves impostos pelas autoridades russas) e das condições de vida extremamente duras nas frentes pioneiras para onde foram encaminhados pelas autoridades brasileiras ou pelas empresas de colonização. Sobretudo, dizem muita coisa a respeito da condição social do imigrante, que, por sua vez, são reveladoras das relações e práticas cotidianas nas áreas coloniais no período da grande emigração para o Brasil. Os dados sobre a mortalidade - na viagem e nas próprias colônias - e as referências às epidemias, por exemplo, raramente aparecem na documentação oficial (cf. Seyferth, 1999). No entanto, a perda de pessoas muito próximas, principalmente parentes, também faz parte dos discursos que constroem a identidade do imigrante, em uma definição em que está implícita a ideia de sofrimento e provação (marcada, as vezes, por pertencimentos religiosos) [...] Enfim, o uso desse tipo de documento remete a própria tradição metodológica da Antropologia, inicialmente voltada para as sociedade sem escrita (caso da "história de vida' e registros similares), da Sociologia e da Psicologia Social, observada no trabalho de Thomas e Znaniecki e nos estudos da imigração realizados a partir de teorias de assimilação e aculturação. Submetidos adequadamente à crítica, dada a defasagem temporal, esses procedimentos metodológicos esclarecem muito mais do que trajetórias individuais, pois colocam em destaque alguns elementos fundamentais constitutivos dos processos migratórios. (SEYFERTH, 2005, p. 48)

Com relação ao estudo da imigração em São Paulo, também têm sido fundamentais os documentos de natureza autobiográfica, principalmente por retratarem as vivências dos imigrantes a partir deles próprios. Muitos pesquisadores têm procurado recorrer a famílias e instituições para aprofundar seus estudos sobre alguns grupos.

Em nossos estudos, conseguimos localizar e analisar alguns documentos que para nós foram fundamentais para a compreensão de alguns grupos de imigrantes com os quais trabalhamos, abordando o século XIX e início do XX (europeus e orientais), com foco principalmente nas questões étnico culturais e educacionais, no contexto em que os imigrantes se inseriram, em áreas urbanas ou rurais.

Anotamos aqui algumas dessas fontes e suas contribuições.

Desse conjunto, destacamos o livro escrito por Thomaz Davatz (1951), talvez o documento mais antigo, mais complexo e importante sobre a imigração em São Paulo, sendo assim considerado também por muitos estudiosos. $\mathrm{O}$ autor trata de aspectos variados do processo imigratório no momento em que a substi- 
tuição do trabalho escravo por mão de obra livre estrangeira começava a ser proposta como alternativa à lavoura de café paulista. Referese às primeiras levas de imigrantes vindos da Europa.

Em São Paulo, os imigrantes trabalhavam como colonos sob o sistema de parceria; nesse sistema, não eram donos das terras que cultivavam, trabalhavam para um fazendeiro, com o qual dividiam os lucros da produção, geralmente de café. Segundo Simson (1997), os alemães que começaram a vir para essa Província, a partir de 1846, tiveram a viagem subvencionada pelos fazendeiros de café, que os mantinham ligados às suas fazendas por meio dos contratos de parceria por eles assinados, que envolviam a mão de obra familiar. Muitos alemães enfrentaram problemas com os fazendeiros por causa desses contratos, que os mantinham presos às propriedades através das dívidas que contraíam. São as vivências desses colonos e seus conflitos que Davatz (1951) anotou em sua obra.

A autobiografia de Thomas Davatz é obra de grande importância, também para o campo da educação, pois, como imigrante, foi mestre -escola na fazenda Ibicaba, uma das primeiras em São Paulo a trazer colonos europeus para trabalharem na lavoura do café - trabalho até então executado pelos escravos. As memórias de Davatz (1951) remetem aos primeiros tempos da imigração, em meados do século XIX. Trata-se de livro escrito após o retorno do autor para a Europa, e o que chama a atenção, sendo a edição inicial realizada em 1858, em Chur, Suiça e publicado em português no Brasil só em 1941. É considerado por muitos estudiosos um documento fundamental sobre os primeiros tempos da imigração.

Antes de sua partida da Europa (Suiça), Davatz, que era mestre-escola, foi incumbido, em sua terra natal, de elaborar relatório detalhado sobre o processo de imigração do grupo, como se pode constatar pelo documento anexo à autobiografia. A comissão apresentou ao mestre-escola um longo questionário, abordando os seguintes temas: assuntos gerais, assuntos relativos ao culto, ao ensino e à beneficência, assuntos políticos e assuntos econômicos (DAVATZ, 1951, p. 238-241). A partir das observações que realizava e dos contatos que estabelecia, Davatz explicita no texto sua estranheza com a nova situação de colonos, com todas as implicações que a mesma impunha, especialmente com o controle que sobre os mesmos era exercido, assim como com a vida dura que thes era imposta e o que julgava serem injustiças e expropriações, pois, a partir dos contratos iniciais que thes foram apresentados, esperava formas diferentes de trabalho e de vida. 0 autor descreve em detalhes o processo migratório do grupo, as dificuldades várias enfrentadas pelos colonos na fazenda Ibicaba, assim como em outras fazendas sobre as quais tinha notícias; trata dos conflitos ocorridos entre os colonos e os seus contratantes, que levaram a movimento considerado de rebelião e intervenções dos poderes públicos

Davatz foi um dos 'leaders' dessa revolta. Dominado o levante pela polícia, Davatz obteve licença para voltar à Suiç̧a. (DAVATZ 1951, p. 3)

Para evidenciar tais questões, aponta na obra o cotidiano de trabalho e os conflitos gerados no exercício das atividades dos colonos com os fazendeiros.

Como mestre-escola e protestante, Davatz fez duras críticas à forma como os protestantes eram tratados no contexto em que a religião católica predominava, assim como à precariedade do sistema educacional (então inexistente).

O que acabo de narrar mostra bem que, mesmo quanto à educação e à religião as condições dos colonos são extraordinariamente precárias e se tornariam francamente deploráveis se eles não recebessem algum amparo. [...]. Não direi 
até onde nos conduziriam tais planos e ninguém porá em dúvida uma coisa, a saber que os colonos, em certos lugares, se veem em maior dificuldade para se libertarem de que os próprios escravos pretos, que não tem dividas a pagar e que poderiam usar, na compra de sua liberdade, os extraordinários que ganham em certas ocasiões, ou em domingos e feriados. Até aqui, de um modo geral, os colonos não sofreram castigos corporais de parte dos feitores. É certo que em casos isolados já se registraram tentativas de agressão contra eles. [...] E as prisões, as multas em dinheiro, que podem ir de $1 \$ 000$ a $100 \$ 000$ por delitos tais como hospedagem a estranhos, saídas da fazenda sem licença prévia, protestos por irregularidades na pesagem ou medida dos gêneros, queixas aos magistrados, e essas penas impostas não pelas autoridades competentes, mas pelos senhores fazendeiros ou diretores, simples particulares, que não as revogam senão em circunstâncias especiais? Tudo isso não equivale bem aos açoites se nos lembrarmos de que as vítimas são pessoas vindas de países civilizados às quais se procura convencer insistentemente de que são livres? E no entanto tais coisas se têm assinalado. Eu próprio tive conhecimento de semelhantes fatos no Brasil e de outros fui informado pelo Dr. Heusser. Será exagero, diante de tudo isso, dizer-se que os colonos se acham sujeitos a uma nova espécie escravidão, mais vantajosa para os patrões do que a verdadeira, por recebem os europeus por preços bem mais moderados do que os dos africanos (um bom africano custa hoje mais de cinco mil francos) sem falar no fato do trabalho dos brancos ser mais proveitoso do que o dos negros? No caso dos primeiros os patrões têm mais vantagem de poder capturá-los sem maiores riscos, sem ter de mandar busca-los do outro lado do Oceano, pois são mandados diretamente para as fazendas. E essa escravidão pode ser empreendida sob o amparo da lei. Estou certo de como aquele que peses bem tudo quanto foi dito não hesitará em afirmar que não exagerei em nada na minha conclusão: os colonos sujeitos a esse sistema de parceria não passam de pobres coitados miseravelmente espoliados, de perfeitos escravos, nem mais nem menos. (DAVATZ, 1951, p. 123-124)
Se a narrativa de Davatz foi sendo construída a partir do encargo que recebeu de elaborar um relatório circunstanciado, nas páginas finais o autor é contundente ao expor o objetivo central que acabou atribuindo à sua obra: a de servir como alerta aos europeus que desejassem imigrar, demovendo-os desse intuito. São páginas e páginas justificando sua posição. Selecionamos só alguns trechos, mas que deixam clara a intencionalidade do livro:

A todos os filântropos de todos os países em questão, particularmente funcionários, sacerdotes, professores, jornalistas, livreiros, etc. que façam o possivel pela ampla divulgação dêste livrinho, a fim de que seu principal objetivo - assistência aos colonos e a redução ou supressão da febre emigratória - possa ser mais fàcilmente atingido.[...] (DAVATZ, 1951, p. 212) [...] E assim salvaremos milhares de irmãos de uma terrivel desgraça, ao mesmo tempo em que fecharemos a outros milhares o caminho da desolação. Deus ouça essas palavras! E que êste livrinho, dado o fim a que se destina, possa seguir seu caminho amparado nas bênçãos do senhor! (DAVATZ, 1951, p. 230)

O historiador Sérgio Buarque de Holanda, que foi tradutor da obra para o português e elaborou um longo prefácio, destacou a importância dessa autobiografia; como escreveu:

[...] Livro de partido, mas também de boa fé, êle é a expressão e o prolongamento da vida de um pobre colono perdido num mundo hostil às suas aspirações. Consideradas nesse aspecto é que as memórias de Davatz poderão ser apreciadas em seu justo valor. (DAVATZ, 1951, p. 35)

Consideramos que se trata de obra de referência obrigatória sobre o período, pois é o olhar do imigrante sobre os vários aspectos de sua vivência e do grupo, naquele momento histórico, evidenciando elementos que geralmente não constam dos documentos elaborados pelos fazendeiros e pelos órgãos públicos da época. O fato de ter sido publicado só 83 anos depois no Brasil já é um indicador de 
como esse olhar do sujeito imigrante não interessava aos daqui.

Publicadas no Brasil em 1956, quase simultaneamente à obra de Davatz, também cartas escritas por Ina von Binzer, educadora alemã, referem-se a sua vivência em fazenda no Estado de São Paulo, de 1881 a 1883. As cartas, que haviam sido enviadas para uma amiga na Alemanha, foram publicadas em português em forma de livro pela Editora Anhembi, com o título original de Alegrias e tristezas de uma educadora alemã no Brasil. No prefácio da primeira edição, o historiador Paulo Duarte já observava:

É o título de um dos mais curiosos livros de 'brasiliana' publicado no século passado, tão rico de obras interessante sôbre o Brasil. Tratase de uma edição alemã, de mil oitocentos e oitenta e tantos, na qual é narrada a vida de uma professora alemã que viveu na fazenda de uma das velhas famílias de $\mathrm{S}$. Paulo e outros lugares daqui e do Rio. (BINZER, 1956, p. 11)

Tendo vindo como preceptora de filhos de fazendeiro, a educadora, assim como várias colegas de profissão, residia junto à família do proprietário. Nas cartas que escreveu, também critica a precariedade do sistema educacional e, principalmente, a inexistente educação para filhos de escravos:

A lei da emancipação de 28 de setembro de 1871 determina entre outras coisas aos senhores de escravos, que mandem ensinar a ler e a escrever a todas essas crianças. Em todo o Império, porém, não existiu talvez nem dez casas onde essa imposição seja atendida. Nas fazendas sua execução é quase impossível... No interior, não há os mestres-escolas rurais como na nossa terra, assim sendo o fazendeiro ver-se-ia obrigado a mandar selar 20 a 50 animais para levar os pretinhos à vila mais próxima, geralmente muito distante; ou então teriam de manter um professor especial para essa meninada... Essas questões apresentam diversas soluções, mas o fato é que ninguém aqui faz coisa alguma, de maneira que as crianças nascem livres, mas crescem sem instrução e no futuro estarão no mesmo nível dos selvagens, sem gozar nem mesmo das vantagens dos escravos, que aprendem este ou aquele trabalho. (BINZER, 1956, p. 104)

Esse não atendimento educacional era também vivenciado pelas famílias de imigrantes e de trabalhadores nacionais livres.

As cartas de von Binzer, diferentemente das obras de T. Davatz e R. Pastor (abordada a seguir), evidenciam o olhar de uma imigrante alemã que não trabalhou na lavoura e que vivenciou em São Paulo o cotidiano de famílias da elite cafeeira, mas que registrou as grandes diferenças sociais existentes, principalmente com relação aos escravos. Como educadora, também fez comparações entre a forma de educar e as práticas pedagógicas prescritas na Alemanha e o que conseguia realizar em São Paulo.

Outro documento autobiográfico que consideramos importante em nossa pesquisa foi o livro de memórias "Raboné, de colono a professor", escrito também pelo professor Raimundo Pastor (1974). Tendo escrito dois livros, no primeiro, relatou a história de sua vida no interior do Estado de São Paulo (Região Sorocabana), desde que, ainda menino, veio da Espanha com a família, até se tornar professor, descrevendo como a educação era vivenciada pelos trabalhadores, geralmente estrangeiros, que viviam nas fazendas de café, neste período da Primeira República. O relato do autor refere-se ao período de 1900-1919, durante o qual seu pai e a família trabalharam em fazendas de café, sob formas variadas de contrato, como colonos (aos 10 anos de idade, os filhos passavam a trabalhar).

Nessa obra, o autor evidencia a preocupação constante do pai imigrante em dar instrução aos filhos; no seu dizer, "aprender a ler, escrever e contar em brasileiro". Segundo ele, essa aspiração interferia, algumas vezes, 
nas suas decisões sobre propostas de contrato de trabalho. Como não havia sempre escolas nas fazendas por onde trabalhava, nem nas proximidades, o pai chegou certa vez a contratar o próprio administrador da fazenda para dar aulas aos três filhos, pagando para tanto dois mil réis por cabeça. Mas a chance de frequentar escolas só surgiu quando a família ia trabalhar em fazenda próxima a Botucatu, podendo assim, os filhos cursarem a escola noturna na cidade. Pastor entrou na escola com vinte anos, e seus irmãos com dezoito e quinze. Tinham grande interesse pelo estudo e deixavam de jantar para poderem chegar em tempo à aula (PASTOR, 1974). Como afirmou no livro: "sobravam professores e faltavam escolas. Não se criavam escolas no meio rural". Terminaram o curso primário com sucesso, continuando, entretanto, a trabalhar na roça. Por insistência de seu professor e por desejo próprio de continuar estudando, o autor cursou a Escola Normal, formando-se professor. Embora já adulto, a família sempre o estimulou e arcou com a sobrecarga de trabalho e despesas decorrentes do seu estudo, pois, para tanto, deixara de trabalhar. É interessante destacar as observações que fez sobre o comportamento de desprezo dos colegas da escola normal com relação ao imigrante pobre da zona rural (PASTOR, 1974, p. 342).

Formado professor, segundo ele, sua situação não melhorou, pois era difícil conseguir vaga para substituir, dado que não havia escolas rurais, e nas cidades só se conseguia com "cartucho político", e ele era imigrante e pobre. Seu primeiro emprego foi na zona rural, como professor dos filhos do administrador de uma fazenda, trabalho que deixou quando foi criada nesta mesma fazenda uma escola mista, que os meninos passaram a frequentar (PASTOR, 1974, p. 134, 313). Depois conseguiu uma escola para lecionar no Vale do Ribeira, expe- riência que narrou no segundo livro, também obra importante para o conhecimento da precariedade do sistema educacional paulista e das demandas da população por escola (PASTOR, 1970).

As anotações do autor levaram-nos a presumir que, se muitos trabalhadores livres que vieram como imigrantes eram analfabetos ou não frequentavam escolas, o problema era antes resultante da falta das mesmas escolas, do que da não disposição de frequentá-las. 0 empenho dos pais era grande para que estudassem. É interessante anotar que a autobiografia de Pastor se refere a suas experiências de infância e juventude, como imigrante, que não diferiam de modo geral das que foram anotadas, em período anterior, por von Bizer, com relação aos escravos.

As cartas e autobiografias nos permitiram compreender como os imigrantes vivenciavam a educação escolar nas fazendas de São Paulo, em que passaram a residir e, também, a forma como a representavam nesse novo contexto. São narrativas elaboradas por educadores, portanto, já imbuídos da importância da educação e com conhecimento da prática pedagógica, o que lhes permitia diagnosticar as grandes deficiências do sistema educacional no meio rural, a inexistência de escolas até para trabalhadores imigrantes livres, que, entretanto, muito as desejavam.

Além das cartas e das autobiografias, também consideramos muito importantes os documentos produzidos por professores e alunos durante suas atividades escolares. Infelizmente são muito dificeis de serem localizados para épocas mais remotas, não só pelas precárias condições de sua manutenção, o quase inexistente material que os protegesse da ação do tempo, mas também porque muito material didático foi destruído a partir das determinações políticas e perseguições do Estado aos grupos imigrantes. (DEMARTINI, 2011). 
De qualquer modo, tivemos acesso, em nossas pesquisas, a cadernos de imigrantes alemães e japoneses.

Com relação aos imigrantes alemães, localizamos vestígios da prática pedagógica da escola de Friburgo, construída em 1878, nas cercanias de Campinas: um caderno de anotações que se supõe fossem para preparar aulas, pertencente ao professor da escola, com datas de 20 de novembro de 1905 a 1906 (escritas em algarismos romanos) e outro caderno da aluna Balbina, iniciado em 1928 e encerrado em 1930; também uma prova escolar, da aluna Erotide, de 1938. Simson, explicita a construção da escola pelos próprios imigrantes:

[...] A construção da escola local foi uma das primeiras decisões da comunidade friburguense. Assim que perceberam que não adiantava esperar pelas autoridades locais eles assumiram a responsabilidade da educação dos seus numerosos filhos. Eles decidiram construí-la no fim do ano de 1878 e para tanto criaram a Associação Escolar. Em outubro do ano seguinte o prédio da escola e a casa para o professor, que viria da Alemanha, já estavam prontos e uma grande festa foi realizada para comemorar essa grande conquista. (SIMSON, 1997, p. 70)

A observação do conteúdo dos documentos acima descritos permitiu-nos levantar alguns pontos para a discussão da forma como imigrantes vivenciavam a experiência educacional a partir de suas culturas de origem, em intersecção com a(s) cultura(as) do país de adoção. Assim, pudemos verificar que, por meio das anotações dos cadernos, que as línguas estavam neles presentes. Nos dois cadernos, há partes escritas em português, outras em alemão; assim, considerando que a pressão do Estado brasileiro, e, de modo especial, do governo paulista, sobre a educação dos estrangeiros manifestou-se mais claramente só a partir da Primeira Guerra Mundial, podemos supor que os alemães de Friburgo tentavam, desde pelo menos o final do século XIX, desenvolver formas de integração à sociedade brasileira. A presença de lições de gramática portuguesa indica a preocupação com o aprendizado dessa língua, fundamental para seu relacionamento com a sociedade mais ampla; nessa direção, também se observa a presença de poesias e contos brasileiros, assim como a preocupação com que os alunos aprendessem a pensar e a problematizar nas duas línguas. A presença da cultura alemã evidencia-se por meio da gramática, da literatura, da geografia, da história e dos valores religiosos fortemente presentes nos dois cadernos. Entretanto, a prova de 1938 é toda ela laudatória da nação brasileira, não contento nenhuma palavra em alemão. Não podemos esquecer que foi justamente sob o governo ditatorial de Getúlio Vargas, que o controle sobre os imigrantes foi intensificado e a política de assimilação dos mesmos desenvolvia-se principalmente por meio do campo educacional, visando a não constituição ou eliminação de "quistos" étnicos em território nacional (DEMARTINI, 2004; 2006a; 2006b).

Sobre os japoneses, foram poucos os cadernos localizados. Dois cadernos referem-se a aulas de culinária, consideradas atividades importantes, pelas famílias japonesas, na formação da jovem, preparando-a para o casamento. É interessante destacar que essa dimensão do quotidiano registrada nos cadernos de duas imigrantes - o aprendizado da culinária assim como o do corte e costura e da pintura, ambos não se dissociavam em algumas escolas japonesas do aprendizado da escrita, da leitura, do cálculo e demais conhecimentos escolares tradicionais. Assim, por exemplo, a escola de D. Akama, como ficou conhecida, sendo criada em São Paulo por ela e pelo marido, em 1932, inicialmente para o atendimento só de meninas e jovens, ministrava o curso de corte e costura: 
[...] Em agosto de 1933, as aulas não mais se restringiam a corte e costura, pois havia enfim, tudo o que era necessário para uma futura dona de casa. A escola atendia à clientela da colônia japonesa do interior, sendo que $70 \%$ das alunas eram de origem japonesa. A partir de 1935, com a institucionalização dos exames de habilitação do magistério profissional de corte e costura, a escola criou um currículo para preparar as candidatas para tal exame. Aproximadamente quarenta jovens conseguiam aprovação anualmente, e depois abriam suas escolas no interior do estado. [...] Esses cursos que utilizavam o mesmo material do Japão eram rápidos, durando de três a seis meses ou até um ano; o curso de língua japonesa era de quatro anos. Havia professores contratados do Japão, universitários, que davam três horas de aula. As aulas de português eram ministradas por uma professora brasileira. Quando a escola funcionava numa casa alugada na rua Conselheiro Furtado, possuía vinte alunas em média, que ficavam em regime de internato; ao mudar para a rua São Joaquim, o número de alunas aumentou para cento e cinquenta, das quais mais ou menos trinta eram internas e as demais voltavam todos os dias para casa. (DEMARTINI, 2000, p. 60-61)

Os cadernos das imigrantes referem-se a esta dimensão da formação das meninas e jovens japonesas, que permitisse que fossem "boas esposas" e, ao mesmo tempo, que pudessem colaborar economicamente com a família, seja preparando alimentos ou confeccionando roupas.

Julgamos importante incorporar, também, os documentos que remetem aos imigrantes, mas a partir do olhar dos paulistas. É o caso do livro de Hermengarda Leme Leite Takeshita: Um grito de liberdade - uma família paulista no fim da belle-époque, publicado em 1984 (Alvorada Editora e Livraria Limitada), que foi incorporado a minhas pesquisas, quando procurava realizar entrevistas com professores que haviam atuado junto a populações rurais do Estado de São Paulo; a sua leitura foi-me indicada por uma colega escritora, que conhe- cia meus estudos, pois Hermengarda correspondia ao perfil de professora que interessava às reflexões que eu vinha desenvolvendo, era autora de várias obras literárias (Sakurá em 1937 e vários contos), mas já havia falecido; entretanto, sua autobiografia, com 337 páginas, permitia várias leituras do período da Primeira República, sobre a experiência dela e de seu marido japonês, como educadores. Na primeira análise que realizei, a obra permitiu-me verificar, por meio das experiências de Hermengarda como professora rural, as relações entre escola e população rural e também que eu observasse alguns de meus entrevistados, sob um outro olhar: Hermengarda foi professora de uma escola cujo diretor e um aluno japonês foram por mim entrevistados. É importante destacar esse fato: no processo de pesquisa, ocorrem diálogos entre as autobiografias escritas e as histórias de vida oralmente obtidas. Essa autobiografia conduziu-me a realidades inesperadas, pois, por meio de sua leitura, tomei conhecimento de que o marido da autora, Takeshita, havia sido professor da primeira escola japonesa da cidade de São Paulo, a famosa Escola Taicho, na Liberdade. Dessa forma, com o auxílio da editora do livro, consegui localizar o endereço de Hermengarda e entrevistar seu marido, que ainda estava vivo e residindo no centro de São Paulo; seus relatos foram muito importantes para a ampliação de minhas reflexões sobre as escolas paulistas e o aprofundamento das questões sobre os grupos de imigrantes e a educação.

É preciso observar que quando os documentos autobiográficos foram redigidos no momento mesmo das vivências dos sujeitos, os fatos geralmente ganham maiores detalhes, assim como estão explicitados os sentimentos daqueles momentos - é o caso dos relatos de Davtz (1951) e de von Binzer (1956). Quando os textos foram escritos a posteriori, caso da obra do Raymundo Pastor, são permeados pelas se- 
leções que a memória vai registrando, com o passar do tempo, alguns detalhes às vezes não sendo incorporados nas narrativas.

De qualquer forma, são narrativas que muito contribuem para o conhecimento das experiências migratórias.

\section{O tempo presente e as narrativas} orais de imigrantes: a relação pesquisador e sujeitos na produção do conhecimento

Para períodos mais recentes, as possibilidades de acesso aos imigrantes ampliam-se, pelo fato de que as fontes orais obtidas por meio de depoimentos ou histórias de vida são acessíveis, em inúmeros casos, sendo produzidas no momento das pesquisas, ou coletadas em acervos de instituições, geralmente constituídos pelos próprios imigrantes, preocupados em reconstruir sua história, preservar elementos de sua cultura de origem e as memórias do grupo. Atualmente, até recursos de internet vão se tornando usuais para o acesso aos sujeitos que vivenciaram processos migratórios.

A retomada de pesquisa qualitativa, nos anos de 1980, parece ter estimulado a realização de entrevistas com imigrantes. Por um lado, as Ciências Sociais e a Antropologia retomaram sua antiga tradição no Brasil, agora também influenciada pelas discussões sobre a pesquisa biográfica levada a efeito em vários centros de pesquisa, na Europa e nos Estados Unidos. Um marco nessa caminhada foi o Congresso Internacional de Sociologia de 1980, realizado em Upsala, em que vários pesquisadores refletiram sobre a importância da abordagem biográfica. Por outro lado, também no campo da História, as discussões da Nova História estimularam a incorporação das fontes orais na produção do conhecimento, instituindo-se até como a nova forte tendência, que passou a ser denominada de História Oral.
Na Psicologia, o clássico trabalho de Eclea Bosi (1983) sobre as memórias de velhos despertou também as atenções para a importância das entrevistas com os mais velhos.

Seja pelas discussões e novas tendências no campo das Ciências Sociais ou da História, o que se observou é que os sujeitos passaram a ser incorporados à produção das fontes de pesquisa, por meio de suas narrativas orais, obtidas de variadas formas e metodologias. E os imigrantes, como sujeitos constituintes da população e da história brasileira, como já apontamos, foram sendo cada vez mais procurados pelas pesquisas que trilhavam novos caminhos na produção de conhecimento sobre os processos de deslocamento dos vários grupos e em lugares muito diversos do país. Também as discussões que ocorriam em algumas áreas sobre as questões da memória permitiam vislumbrar que era possivel trabaIhar com as memórias de pessoas mais velhas, desfazendo-se a ideia de que os relatos sobre situações pretéritas eram sempre saudosistas e fantasiosos. Alguns autores contribuíram para essa discussão, no tocante às memórias do passado.

A partir dos anos de 1990, começou a aumentar a produção de pesquisas que recorriam à abordagem biográfica para o estudo de grupos de imigrantes, o que se evidenciava nos congressos e em publicações.

Em virtude da intensificação dos estudos sobre imigração, com a criação de grupos de pesquisa em diversas instituições, existindo desde 1998 o grupo de trabalho da ANPOCS sobre Migrações Internacionais, foi proposto, por esse grupo, a elaboração de um livro com as reflexões metodológicas sobre a abordagem do fenômeno migratório. 0 foco foi chamar a atenção para as várias possibilidades de pesquisa, entre as quais a pesquisa baseada em relatos orais de imigrantes. Ao refletir sobre essa questão, observei que era preciso inten- 
sificar os estudos recorrendo a fontes orais e imagéticas, tais como os realizados por Bela Feldman Bianco (1995), sobre imigrantes portugueses nos Estados Unidos, mas que muitas pesquisas já estavam recorrendo às fontes orais com relação a diversos grupos de imigrantes (DEMARTINI, 2005). Naquele momento, algumas instituições também coletavam narrativas orais de imigrantes para a constituição de arquivos históricos para consulta (Museu da Pessoa, Memorial do Imigrante, Museu da memória judaica etc.).

No mesmo texto acima citado também chamemos a atenção para a especificidade do estudo com narrativas orais de imigrantes, recorrendo a histórias de vida e depoimentos, pois, em muitos casos, não há um conhecimento do universo de informantes para que se possa estabelecer a priori uma amostragem, ou mesmo um critério de seleção dos que serão entrevistados. Como já afirmado em vários momentos, as pesquisas com imigrantes envolvem uma construção sistemática durante o processo de trabalho, uma atenção contínua sobre a problemática pesquisada e, principalmente, uma escuta atenta do pesquisador sobre o que os imigrantes vão relatando, o que implica que o processo de seleção dos entrevistados geralmente é revisto continuamente, assim como as temáticas das quais se partiu. As sugestões são necessariamente incorporadas, durante o processo, levando-nos a afirmar que não só o pesquisador que recorre a histórias de vida e a depoimentos constrói os documentos com os entrevistados, elege os informantes da história e os fatos que vai analisar sobre suas experiências, mas também que a pesquisa é fortemente influenciada em seu desenrolar, pela incorporação desses sujeitos na produção do conhecimento. Como foi bem observado por Ferrarotti (1981), há uma dialogicidade em todo esse processo que envolve a aborda- gem biográfica, uma troca de experiências e saberes entre os sujeitos envolvidos.

Por tais motivos, também se pode afirmar que não há "receitas metodológicas" prontas, isso é, caminhos predefinidos para os estudos que se referem a imigrantes. Se há algumas características que assemelham os processos de deslocamento e as vivências dos imigrantes, como foi bem observado por alguns estudiosos (SAYAD, 2000; ROCHA-TRINDADE, 2005; FELDMAN-BIANCO, 1995; BONVIN e PONCHAUD, 1981, entre outros), há, entretanto, uma multiplicidade de situações e diversidade entre os processos migratórios, entre os grupos de imigrantes, entre os imigrantes do mesmo grupo, principalmente considerando-se os diferentes contextos de saída e de chegada, com todas as implicações econômicas, políticas, culturais, étnicas, em diferentes momentos históricos.

A realização de pesquisas tendo como lócus o Estado de São Paulo, permitiu-nos entrevistar imigrantes de diferentes grupos.

Inicialmente, abordamos as famílias de imigrantes japoneses, tanto as famílias que vieram na primeira fase da imigração (19081932), como as que vieram no pós Segunda Guerra Mundial. Entrevistei também famílias alemãs que vieram para São Paulo, no mesmo período. Depois, focalizei famílias portuguesas que vieram na primeira metade do século $\mathrm{XX}$, para, a seguir, abordar os fluxos de portugueses, luso-africanos e africanos que vieram na segunda metade do século passado. Trabalhei assim, com imigrantes cuja invisibilidade era grande na sociedade brasileira, assim como com aqueles que a "perturbavam", dadas suas características étnico-raciais. Nos últimos anos, passei a focalizar também os deslocamentos mais recentes do século XXI, procurando compará-los com as imigrações anteriores.

Para abordar as histórias de imigrantes de outros territórios, ocidentais e orientais, foi preciso realizar leituras que permitissem en- 
tender, a partir de uma perspectiva histórica, os contextos socioeconômicos e políticos dos quais vieram ou pelos quais passaram, recorrendo, para tanto, aos estudos de pesquisadores brasileiros e outros que haviam estudado tais contextos. Foram muitos os autores que auxiliaram na compreensão dos contextos europeu, africano e japonês.

O processo de realização de entrevistas apresentou especificidades, conforme o grupo pesquisado, variando também no interior de cada um, das diferentes gerações abordadas, das posições assumidas pelo sujeito no grupo de imigrantes e na sociedade mais ampla. Cada entrevista, seja a mais extensa, mais sucinta ou a mais evasiva, contribuiu para o conhecimento do grupo, de suas vivências e de seus problemas. Dificilmente as entrevistas se assemelharam, em seu desenvolvimento e conteúdo, sendo essa a riqueza que os relatos podem trazes aos estudos sobre imigração: por meio deles, podemos apreender uma variedade de representações e visões de indivíduos socialmente inseridos em posições diferentes, com trajetórias e projetos de vida em parte desconhecidos.

Para adotar a perspectiva da abordagem biográfica em pesquisa com imigrantes, é importante que o pesquisador incorpore o que Bastide (1983) chamou de "a poesia como método sociológico", isto é, ficar atento e usar toda a intuição para apreender as sutilezas das narrativas, refletindo sobre as mesmas, sem encaixá-las em leituras e critérios de analise predeterminados, não "empalhando" os fatos sociais, como diria o autor. Ferrarotti também chama a atenção para o fato de que o pesquisador deve interrogar-se sobre os temas significativos que surgem dos relatos, sobre os momentos cruciais, sobre as tomadas de decisões (FERRAROTTI apud JOBERT, 1984, p. 29). No caso das famílias que se deslocaram em momentos de guerra, por exemplo, suas histórias reme- tiam a momentos de crise aguda do sistema colonial português, que as levou à migração. Balandier (1951; 1969) também alertava sobre a importância dos momentos de crise para a apreensão dos fenômenos sociais e das relações que se estabelecem na sociedade, em determinadas épocas e contextos.

Destaco inicialmente algumas questões que foram determinantes do ponto de vista metodológico, pois implicaram em procedimentos diferenciados, conforme os sujeitos abordados. Assim:

- a constatação da grande heterogeneidade dos imigrantes, considerando seus contextos de origem e suas condições socioeconômicas e culturais, além das étnico-raciais;

- os momentos em que ocorreram os deslocamentos e a forma como a saída foi prioridade, como projeto "pensado" pelo imigrante, como saída "forçada" por situação de guerra;

- a representação do Estado Brasileiro sobre cada grupo e as facilidades e dificuldades impostas pela legislação e redes de apoio;

- a forma como a sociedade paulista representou cada grupo e as diferenciadas formas de relacionamento estabelecidas, os estranhamentos maiores, ocorrendo em relação aos orientais (japoneses) e aos africanos negros;

- a língua falada pelos imigrantes.

A heterogeneidade levou-nos a encontrar formas até então não pensadas para realizar a aproximação com os imigrantes mais reticentes, as diferenças de língua, muitas vezes se interpondo, e as hierarquias definidas culturalmente, exigindo grande atenção por parte dos pesquisadores para realizar a pesquisa com o respeito e a responsabilidade necessários.

Do ponto de vista do conteúdo das análises realizadas nas várias pesquisas que rea- 
lizei, pude observar algumas dimensões dos estudos sobre migrações que as narrativas orais permitiram desvendar ou aprofundar, tais como:

a) o conhecimento dos contextos de saída, geralmente não vivenciados pelo pesquisador, mas que os relatos dos imigrantes os levam a conhecer: novas paisagens, novas sociedades, novos personagens, novas histórias, novos conflitos;

b) as especificidades, semelhanças e diferenças entre os contextos de origem e o contexto brasileiro de adoção, em suas várias dimensões (econômicas, políticas, educacionais, culturais, étnicas, religiosas etc.), em diferentes períodos históricos e as implicações pelos deslocamentos empreendidos.

c) com relação ao campo familiar, as relações entre os membros de famílias imigrantes foram, geralmente alteradas com seus deslocamentos, envolvendo separações dos que ficaram no contexto de saída, reencontros com familiares que haviam imigrado muitos anos antes para o contexto de adoção, constituição de novos arranjos familiares e até o retorno de parte de familiares para o contexto de saída ou outros. Especialmente nos deslocamentos ocorridos na segunda metade do XX e no XXI, podemos constatar a constituição de famílias “intercontinentais e mutantes", que vão sendo constituídas em cada contexto por diferentes participantes. Como observamos em narrativas de imigrantes desses tempos mais recentes de globalização, parece haver um tom de "naturalidade", com relação aos afastamentos, ausências, o convívio à distância, embora sempre permeados por fortes emoções.

Nas relações entre os contextos de saída e de adoção, novos elementos parecem ter influenciado a representação da ausência do outro: as novas tecnologias têm, de certa forma, facilitado a manutenção de relações com os que ficaram no contexto de origem. $\mathrm{O}$ emi- grante está ausente, mas, ao mesmo tempo, ele pode se fazer presente, por outros meios, o que em outros tempos só era possivel por meio de cartas, que demoravam até meses para chegar aos destinos, quando chegavam. Podemos pensar que a família teria um capital específico, ligado à afetividade e à emoção, como constatamos em vários estudos do CERU (LANG, 1997). No caso de muitos imigrantes, trata-se do sentimento de pertencer ao grupo familiar mais amplo, e até no desenvolvimento de estratégias para mantê-lo de forma coesa, o que é facilitado pelas comunicações mais frequentes, atualmente disponibilizadas. Entretanto, dependendo das condições de saída, como as enfrentadas por muitas famílias que vieram de Angola e Moçambique para São Paulo, na década de 1970, as relações com o contexto anterior tornaram-se mais dificeis, pois poucos familiares permaneceram, em virtude da situação de guerra. Ao entrevistar as gerações sucessivas dos imigrantes, constatamos como, nesses casos, há dificuldades dos filhos e netos em compreender toda a complexidade das situações enfrentadas pelas famílias. As marcas dos processos migratórios são carregadas pelas gerações.

Com relação aos membros mais jovens das famílias migrantes, observa-se que muitas crianças carregam, em suas experiências de vida, as vivências em diferentes realidades socioeconômicas e culturais. Ficam geralmente sujeitas às decisões dos adultos, quanto ao seu deslocamento, muitas delas podendo ser caracterizadas como "crianças entre o ir e vir", isto é, que ficam afastadas dos pais até imigrarem para o novo contexto, ou até aquelas que fazem a travessia desacompanhadas.

As memórias dos que vieram como pequenos imigrantes remetem aos desafios enfrentados na travessia e nas vivências em terras paulistas. Uma das dimensões que surgem é como, a partir dos estranhamentos iniciais, 
vão aprendendo a conhecer o novo meio, novas pessoas, costumes, sua língua - adquirem novos saberes que só o deslocamento lhes possibilitou.

Nesse processo, os sujeitos fazem comparações com a travessia realizada pelos adultos e os problemas identitários que passam a enfrentar, principalmente quando adultos.

d) com relação ao campo da educação, a constatação do empenho generalizado entre os imigrantes, de diferentes origens, para providenciar a educação dos mais novos. Para tanto, criaram coletivamente centenas de escolas para suprir as deficiências do sistema educacional paulista: escolas alemãs, italianas, japonesas, francesas, além das que eram de orientação religiosa e bastante procuradas, geralmente por famílias que podiam arcar com os custos financeiros. Os vários grupos enfrentaram as restrições do governo paulista ao funcionamento das escolas por eles criadas e, ao longo do século $X X$, desenvolveram formas de convivência com as políticas de Estado, de modo que as escolas pudessem continuar funcionando. Um dos grandes desafios era como ensinar a língua e a cultura do grupo, com as restrições que foram sendo impostas desde a década de 1920, e que foram intensificadas durante o Estado Novo e a Segunda Guerra Mundial; mas muitas conseguiram sobreviver até os dias atuais.

O acesso à educação nem sempre foi possível aos pequenos imigrantes que residiam em regiões mais isoladas. A maior parte, entretanto, conseguiu concretizar os projetos familiares de realizar a educação escolar; para muitos foi possivel chegar a niveis mais elevados de escolarização, já na segunda geração, viabilizando sua inserção em um mercado de trabatho mais qualificado.

e) a inserção econômica dos imigrantes em território paulista foi facilitada por diferentes fatores. Nas levas mais antigas, do século
XIX e início do XX, pelas políticas do Estado, visando atrair imigrantes por meio de viagens subsidiadas pelo trabalho nas lavouras paulistas, além do interesse de outras nações em sua saída. Para alguns grupos foram importantes as redes que foram sendo estabelecidas por vínculos familiares, regionais, religiosos e até identitários, para apoiá-los em sua chegada.

Para muitos, foi fundamental recorrer às qualificações que carregavam das profissões que exerciam em seus contextos de origem para conseguir novos empregos ou desenvolver atividades para as quais estavam preparados, principalmente nas áreas urbanas. Em várias famílias, as gerações familiares continuavam atuando nas mesmas áreas que a primeira geração, mesmo quando atingiam níveis superiores de escolaridade, o que ocorreu com várias famílias portuguesas; em outros casos, outras profissões passaram a ser exercidas e não mais a tradicional da família. 0 processo migratório também permitiu uma maior incorporação das mulheres a um mercado de trabatho mais diversificado.

\section{Algumas anotações para reflexão}

Nossa intenção, ao refletir sobre a pesquisa de abordagem biográfica nos estudos migratórios, foi evidenciar a importância das fontes que podem ser trabalhadas com relação a diferentes grupos, em diferentes épocas, chamando a atenção para pontos que consideramos fundamentais no estudo das migrações atuais. Assim, a necessidade de:

- intensificar a construção e a coleta de fontes produzidas por e com os imigrantes, para que se possa refletir sobre os processos migratórios, para além do ponto de vista do Estado e das políticas públicas, mas com base no olhar dos sujeitos envolvidos; 
- diversificação e complementaridade das fontes na produção do conhecimento;

- incorporação de narrativas produzidas por imigrantes e por sujeitos "outros" não imigrantes;

- utilização de fontes do país de adoção, mas também dos contextos de origem (ou de passagem).

É possivel afirmar que, para a pesquisa sobre imigração, os caminhos são muitos e foram sendo ampliados. A pesquisa, recorrendo à abordagem biográfica, tornou-se fundamental para a discussão das questões envolvendo os imigrantes, principalmente pelo fato de considerá-los como "sujeitos", mesmo quando são considerados como "outros", pela sociedade, e como ameaçadores pelo Estado brasileiro. Mais do que tomar os sujeitos imigrantes e inseri-los na produção do conhecimento, ao abordá-los, o pesquisador também passa a refletir sobre a sua própria atividade e o seu modo de pensar a realidade

A temática da imigração, ao recorrer à abordagem biográfica, questiona o pesquisador tanto com relação ao seu modo de fazer ciência, como ao modo de viver da sociedade, ao colocar em pauta a questão central da alteridade, pois, como já alertava Sayad (2000), a imigração é um fato social total, que envolve a sociedade de partida e o contexto de adoção. 0 "outro" que chega nunca passa despercebido, e isso pode ser constatado tanto em períodos mais remotos como nos dias atuais. No Brasil, os imigrantes sempre foram considerados como "outros", nem sempre como "sujeitos". Tornaram-se números, parte dos estudos econômicos, sociológicos, históricos, mas de certa forma estavam ausentes da produção sobre eles próprios.

Os imigrantes são os mais "estranhos", os "outros" mais visiveis na sociedade (embora alguns grupos de imigrantes sejam mais visíveis do que outros). Mas, trazer à tona sua pre- sença, remete também à discussão dos processos de inclusão e exclusão nela presentes, os critérios de alocação das pessoas e grupos na hierarquia social, os preconceitos e discriminações. As questões relacionadas com os imigrantes levam a sociedade a pensar sobre si própria e ao modo como trata não só os que vêm de fora, mas os que a compõem. Coloca desafios ao Estado, às políticas públicas, às pessoas que passam a "conviver" com os que chegam e até com os que delas não estão próximos, mas que as temem, como tem ocorrido, nas últimas três décadas, na Europa. (DEMARTINI, 2010; SANTAMARIA, 1998).

Nos dias atuais em que os deslocamentos continuam ocorrendo motivados por situações de pobreza ou de guerra, acompanhados muitas vezes por ações de violência e conflitos, esse é um desafio que cabe à pesquisa biográfica e àqueles que dela se aproximam: tornar os sujeitos imigrantes menos "estranhos", mais presentes, parte da mesma sociedade.

\section{Referências}

ATLAS da População do Estado de São Paulo (Governo do Estado de São Paulo). São Paulo: Fundação SEADE, 1991.

BALANDIER, G. La situation coloniale: approche théorique. Cahiers Internationaux de Sociologie, Paris, v. 11, p. 44-79, 1951.

BALANDIER, G. Anthropogie politique. 2. ed. Paris: Presses Universitaires de France, 1969.

BASSANEZI, Maria Silvia C. B. Imigrações internacionais no Brasil: um panorama histórico. In: PATARRA, Neide Lopes. (Coord.). Emigração e imigração internacionais no Brasil contemporâneo. 2. ed. v. 1. São Paulo: FNUAP, 1996. p. 1-38.

BASTIDE, R., A propósito da poesia como método sociológico. In: PEREIRA DE QUEIROZ, Maria Isaura. (Org.). Roger Bastide: sociologia. São Paulo, Ática, 1983. p. 81-87. (Coleção Grandes Cientistas Sociais, 37). 
BINZER, Ina von. Alegrias e tristezas de uma educadora alemã no Brasil. São Paulo: Anhembi, 1956.

BONVIN, F.; PONCHAUD, F. Insertion sociale des réfugiés du Sud-Est Asiatique (1). Recherche Sociale, Paris, n. 78, avr./jui. 1981.

BOSI, Eclea. Memória e sociedade: Lembranças de velhos. São Paulo: T. A. Queiroz, 1983.

DAVATZ, Thomas. Memórias de um colono no Brasil (1850). 2. ed. São Paulo: Livraria Martins, 1951. (Biblioteca Histórica Brasileira, 5).

DEMARTINI, Zeila de Brito Fabri. Relatos orais de famílias de imigrantes japoneses: elementos para a história da educação brasileira. Educação e Sociedade, São Paulo, v. 21, n. 72, p. 43-72, 2000.

DEMARTINI, Zeila de Brito Fabri. Marcas da guerra em terra distante: relatos de japoneses em São Paulo. História Oral (Rio de Janeiro), São Paulo, n. 7, p. 145-180, 2004.

DEMARTINI, Zeila de Brito Fabri. Pesquisa históricosociológica, relatos orais e imigração. In: DEMARTINI, Zeila de Brito Fabri; TRUZZI, Oswaldo. (Org.). Estudos migratórios: perspectivas metodológicas. São Carlos: UFSCAR, 2005. p. 87-113.

DEMARTINI, Zeila de Brito Fabri. Infância e imigração: questões para a pesquisa. In: FREITAS, M. C. (Org.). Desigualdade social e diversidade cultural na infância e na juventude. São Paulo: Cortez, 2006a. p. 113-153.

DEMARTINI, Z.B.F. Memórias que interrogam: formação e atuação docente. In: SOUZA, E. C.; ABRAHÃO, M. H. M. B. (Orgs.). Tempos, narrativas e ficções: a invenção de si. Porto Alegre: EDIPUCRS, 2006. p. 279-298.

DEMARTINI, Zeila de Brito Fabri. Immigration in Brazil: the insertion of different groups. In: SEGAL, Uma A.; MAYADAS, Nazneen S.; ELLIOTT, Doreen. (Orgs.). Immigration worldwide: policies, practices and trends. New York: Oxford University Press, 2010. p. 409-423.

DEMARTINI, Zeila de Brito Fabri. Imigrantes em diferentes contextos: conflitos e discriminações. Revista Travessias. Braga-PT, 2011, v. 10, p. 183-232.
EUFRÁSIO, Mario. Nota metodológica: capítulo Introdutório de The Polish Peasant in Europe and América. (THOMAS, William I.; ZNANIECKI, Florian). Departamento de Sociologia FFLCH. São Paulo: Universidade de São Paulo, 2006. (mimeo).

FELDMAN-BIANCO, Bela. A criação de uma nação (portuguesa) desterritorializada e a transnacionalização de famílias. Cadernos CERU, São Paulo, n. 6 , p. 89-104, 1995.

FERRAROTI, F. Storia e storie di vita. Roma: Saggi Ascabililarterza, 1981.

IANNI, Otávio. O progresso econômico e o trabalhador livre. In: HOLANDA, Sérgio Buarque de. História Geral da Civilização Brasileira. São Paulo: Difel, 1967. (Tomo 3, v. 3).

JOBERT, G. Entretien avec... Franco Ferrarotti. Éducation Permanente, n. 72-73, p. 25-31, mar. 1984.

LANG, Alice Beatriz da Silva Gordo. (Org.). Família em São Paulo: vivência na diferença. v. 1. São Paulo: Humanitas, 1997. p. 77-95.

MONSMA, Karl. Histórias de violência: inquéritos policiais e processos criminais como fontes para o estudo de relações interétnicas. In: DEMARTINI, Zeila de Brito Fabri; TRUZZI, Oswaldo. (Org.). Estudos migratórios: perspectivas metodológicas. São Carlos: UFSCAR, 2005. p. 159-221.

OLIVEIRA, Márcio de. 0 tema da imigração na sociologia. Revista de Ciências Sociais, Rio de Janeiro, v. 57, n. 1, p. 73-100, 2014.

PASTOR, Raimundo. Alegrias, agruras e tristezas de um professor: recordações de Xiririca, Itanhaém, Iporanga e Vila Bela, de 11/07/1919 a 05/1929. São Paulo: Centro do Professorado Paulista; Gráfica São José, 1970.

PASTOR, Raimundo. Raboné, de colono a professor. São Paulo: Centro do Professorado Paulista, 1974.

POLLACK, M. Memória e identidade social. Estudos Históricos, Rio de Janeiro, v. 5, n. 10, p. 200-215, 1992.

ROCHA-TRINDADE, M. B.; CAMPOS, M. C. S. S. (Orgs.). História, memória e imagens nas migrações: abordagens metodológicas. Oeiras: Celta, 2005. p. 99-133. 
SANTAMARÍA, Enrique. Do conhecimento de próprios e estranhos: disquisições sociológicas. In: LARROSA, Jorge; LARA, Nuria Pérez de. (Orgs.). Imagens do outro. Petrópolis, RJ: Vozes, 1998. p. 47-66.

SAYAD, Abdelmalek. O retorno: elemento constitutivo da condição do imigrante. Travessia - Revista do Migrante, São Paulo, v. 13, n. especial, p. 3-32, jan. 2000.

SEYFERTH, Giralda. Imigração, preconceitos e os enunciados subjetivos dos etnocentrismos. Travessia, São Paulo, v. 51, p. 5-15, jan./abr. 2005.

SIMSON, Olga R. de M. von. Diversidade sócio-cultural, reconstituição da tradição e globalização: os teuto-brasileiros de Friburgo-Campinas. In: LANG, Alice B. S. G. et al (Orgs.). Família em São Paulo: vivências na diferença. São Paulo: Humanitas; CERU, 1997. p. 63-75. (Coleção Textos, série 2, n. 7)

TAKESHITA, Hermengarda Leme Leite. Um grito de liberdade: uma família paulista no fim da belle époque. São Paulo: Alvorada, 1984.

THOMAS, Wiliam I.; ZNANIECKI, Florian. The polish peasant in Europe and America: monograph of an immigrant group. v. I. New York: Dover Publications, 1958.

Recebido em: 21.02.2018

Aprovado em: 26.03.2018

Zeila de Brito Fabri Demartini é Doutora em Ciências Sociais, Pesquisadora e Diretora de Pesquisa do Centro de Estudos Rurais e Urbanos (NAP-CERU/USP) e Professora colaboradora da UNICAMP e pesquisadora do CNPq. e-mail:zeila@usp.br

Av. Prof. Luciano Gualberto, 315, Sala 20. Cidade Universitária, São Paulo/SP. Telefones: (11) 3091-3735, (11) $3091-3784$ 